\title{
Acquired Unilateral Cataract
}

National Cancer Institute

\section{Source}

National Cancer Institute. Acquired Unilateral Cataract. NCI Thesaurus. Code C101192.

A cataract in one eye that results from the aging process, an injury, or as a manifestation of a systemic disorder. 